\title{
COVID-19 vaccination and IgG and IgA antibody dynamics in healthcare workers
}

\author{
SABINA ZURAC ${ }^{1,2^{*}}$, LUCIANA NICHITA $^{1,2^{*}}$, BOGDAN MATEESCU ${ }^{3,4^{*}}$, \\ CRISTIAN MOGODICI ${ }^{2}$, ALEXANDRA BASTIAN ${ }^{1,2}$, CRISTIANA POPP $^{2}$, MIRELA CIOPLEA $^{1,2}$, \\ CLAUDIU SOCOLIUC ${ }^{1,2}$, CAROLINA CONSTANTIN ${ }^{2,5}$ and MONICA NEAGU ${ }^{2,5,6}$
}

\begin{abstract}
${ }^{1}$ Department of Pathology, Faculty of Dental Medicine, 'Carol Davila' University of Medicine and Pharmacy, 020021 Bucharest; ${ }^{2}$ Department of Pathology, Colentina University Hospital, 020125 Bucharest; ${ }^{3}$ Internal Medicine Department, 'Carol Davila' University of Medicine and Pharmacy, 020021 Bucharest; ${ }^{4}$ Department of Gastroenterology, Colentina University Hospital, 020125 Bucharest; ${ }^{5}$ Immunology Laboratory, 'Victor Babes' National Institute of Pathology, 050096 Bucharest; ${ }^{6}$ Doctoral School of Biology, Faculty of Biology, University of Bucharest, 050095 Bucharest, Romania
\end{abstract}

Received April 1, 2021; Accepted May 27, 2021

DOI: $10.3892 / \mathrm{mmr} .2021 .12217$

\begin{abstract}
Given the current outbreak of coronavirus disease 2019 (COVID-19) and the development and implementation of mass vaccination, data are being obtained by analyzing vaccination campaigns. In the present study, 69 healthcare workers who were exposed to patients with severe acute respiratory syndrome coronavirus-2 were monitored for specific immunoglobulin ( $\mathrm{Ig}) \mathrm{G}$ and $\mathrm{IgA}$ levels at different time periods. Prior to vaccination, after the first round of vaccination at 21 days (when the second dose of vaccine was administrated) and 24 days after the second round of vaccination, with an mRNA-based vaccine. The basal IgG and IgA levels in previously infected subjects and non-infected subjects notably differed. Vaccination increased the $\operatorname{IgG}$ and IgA levels after the first dose in most subjects from both groups, the levels of which further increased following the second round of vaccination. The associations between $\operatorname{IgG}$ and $\operatorname{Ig} \mathrm{A}$ levels following the first and second rounds of vaccination demonstrated that in the entire vaccination group, regardless of prior exposure to the infectious agent, the increment and levels of IgG and IgA were similar. Thus, the levels upon vaccination
\end{abstract}

Correspondence to: Professor Monica Neagu, Immunology Laboratory, 'Victor Babes' National Institute of Pathology, 99-101 Splaiul Independentei, 050096 Bucharest, Romania

E-mail: neagu.monica@gmail.com

Dr Claudiu Socoliuc, Department of Pathology, Faculty of Dental Medicine, 'Carol Davila' University of Medicine and Pharmacy, 7 Dionisie Lupu, 020021 Bucharest, Romania

E-mail: socoliucc@yahoo.com

${ }^{*}$ Contributed equally

Key words: severe acute respiratory syndrome coronavirus-2, antibodies, vaccination were statistically similar irrespective of the starting base line prior to vaccination. In the present study, seroconversion was achieved in all subjects following the second round of vaccination, with similar antibodies levels.

\section{Introduction}

Coronavirus disease 2019 (COVID-19) induced by severe acute respiratory syndrome coronavirus-2 (SARS-CoV-2) has caused the current global pandemic. In the quest for combatting this pandemic, novel drugs and therapeutic approaches for difficult cases, as well as new outlines for clinical management have come forth at an accelerated pace. Various therapies have been tested (1); however, among the tools that could halt this pandemic is the achievement of herd immunity. Herd immunity, also known as community immunity, is reached when a large amount of the population within a community becomes immune to a specific disease and the infectious agent subsequently stops spreading. Thus, the immunized population as a total group would provide protection; not every single individual is immune to the infection as there are also non-immunized individuals alongside naturally or artificially immunized individuals (2). Among the means used to obtain herd immunity, the development of effective and safe vaccines is the most operative. Acknowledging that vaccination should commence as quickly as possible, in July 2020, the SARS-CoV-2 panel of vaccines included 158 vaccine candidates, out of which approximately 20 were in the advanced stages of development namely, mRNA-based vaccines, adenoviruses-based vaccines and pathogen-specific vaccines (3). The vaccines which, during the summer of 2020, were in the advanced stages of clinical testing were based upon inactivated or live attenuated viruses, protein sub-units, virus-like particles, viral vectors (either replicating or non-replicating), DNA, RNA, nanoparticles, each of these types exhibiting unique advantages (4). Of all the vaccines that were in line for approval during the summer of 2020, only a few of these obtained FDA and subsequent EU approval. Therefore, the first mRNA-based vaccine 
(Pfizer-BioNTech) was approved by the FDA and EMA $(5,6)$. The approval of the Moderna vaccine on December 18, 2020 contributed to the list of approved vaccines for COVID-19 (7). Therefore, by February 18, 2021, almost a dozen vaccines were authorized worldwide and up to the date of the publication of the present study, even more may be approved and many more will be in the pipeline of development (8).

The encounter of an organisms with the actual SARS-CoV-2 virus triggers the appearance of specific antibodies, but the dynamics of sero-convention is still under intense studies. It was shown that immunoglobulin (Ig)M antibodies are detectable around the fourth day of infection, increasing until the 20th day when peaks, and then fads away while $\mathrm{IgG}$ appears around the first week of infection and peaks around the first month (9). Nevertheless, it was shown that upon infection seroconversion (IgG or IgM antibodies) takes place simultaneously and the concentrations of the two types of antibodies reach a peak value that does not vary anymore (10). Moreover, in patients with mild and severe forms it was reported that over time the IgM titer gradually increases (11). In oligo-symptomatic patients, lower antibodies titers were detected compared to symptomatic individuals in a high proportion, $40.0 \%$ compared to only $12.9 \%$ in symptomatic patients (12). In respiratory infection, IgM and IgG isotypes were the main immune molecules that characterize humoral immunity, while mucosal and systemic IgA-based immune responses received much less attention (13).

Therefore the vaccination race that begun with an unprecedent speed still has to gather data regarding the specific immune response raised, both from the humoral and cellular immune arms. Acquiring specific immunity upon vaccination is the key goal of an efficient vaccine. Although over the past year, a vast number of studies have been published on humoral and cellular immunity in COVID-19 patients, data regarding immunity raised by a specific vaccine are limited. Therefore, analyzing the specific response of antibodies upon specific vaccination, the present study aimed to investigate the humoral immune response in a homogenous group of healthcare providers with permanent contact with infected patients and samples with SARS-CoV-2 that were subjected to vaccination in the first line of defense in the Romanian population.

\section{Materials and methods}

Subjects. A total of 103 subjects were followed-up between May 2020 to February 2021. The group represents healthcare workers in contact with SARS-Cov-2-infected patients during the present pandemic. Out of the entire group, 69 subjects received the full vaccination protocol and were followed-up for all three determination - 1 day prior to vaccination, 1 day before the second dose and 24 days after the second dose. The inclusion criteria were as follows: Vaccination with both doses on the 6th and 27th January 2021 with Pfizer-BioNTech vaccine, no positive tests for SARS-CoV-2 infection documented by RT-qPCR test, all three blood tests ( 1 day prior to vaccination, 1 day before the second dose and 24 days after the second dose), no other disease or pregnancy during testing. The exclusion criteria of the tested group were as follows: Lack of vaccination in the 6 January 2021 group, lack of one of the vaccination shots, lack of one of the blood sampling from the three-mandatory determinations, presence of active infection documented by standard RT-qPCR in the week prior to first blood sampling, pregnancy, any other condition (flu, inflammatory conditions and so on). The characteristics of the enrolled subjects, such as age and gender are presented in Table I.

Associated co-morbidities of the subjects are presented in Table SI (supplementary material). The group of 69 subjects were vaccinated in January 2021 and they were followed-up before and after vaccination for measurement of the levels of serum IgG and IgA. During this year of follow-up, the entire group was subjected to regular testing from nasopharyngeal swabs of SARS-CoV-2 virus using standard RT-qPCR testing approved by EMA and FDA. Subjects were tested regularly and/or when suspicions to be infected with AllplexTM 2019-nCoV Assay, (Seegene Inc.). At vaccination moment, the subjects that comprised the presented group had the most recent disease 8 weeks prior to vaccination, while the latest documented disease was 8 months prior to the first sampling. Prior to vaccination, out of the entire group, $23.18 \%$ of the subjects had gone through documented COVID-19 (proved SARS-CoV-2 infection by RT-PCR testing).

Vaccination. All the subjects received the Pfizer-BioNTech vaccine at the specified interval according to the supplier instructions. As all the subjects were in the first line of defense in the current pandemic, they received their first vaccine shot on the January 6, 2021 and the second dose on January 27, 2021.

Dynamics of sampling. All the subjects were tested for the presence of $\operatorname{IgA}$ - and IgG-specific antibodies recognizing the S1 domain of the SARS-Cov-2 spike protein beginning from May 2020 in order to follow their immunity upon accidental infection. Following Pfizer-BioNTech vaccination approval, all the subjects received the vaccine. All subjects were tested 1 day prior to vaccination, 1 day before the second dose and 24 days after the second dose.

Blood sampling. Peripheral blood samples from subjects comprising the tested group were collected by venipuncture during the morning hours in blood clot activator tubes (Vacutest Kima). Blood collection was carried out at the Colentina University Hospital. Serum samples, separated by centrifugation $(1,500 \mathrm{x} \mathrm{g}, 10 \mathrm{~min}$ at room temperature) within $4 \mathrm{~h}$ of blood collection, were used for ELISA. Serum samples were stored at $-80^{\circ} \mathrm{C}$ for concomitant testing.

ELISA. Anti-SARS-CoV-2 ELISA (IgG and IgA) kits was used to determine the serum levels of specific $\operatorname{IgG}$ and IgA (EUROIMMUN Medizinische Labordiagnostika AG; code EI 2606-9601A for IgA kit, code EI 2606-9601G for IgG kit). The kits are commercially available, EMA and FDA approved for IVD testing in SARS-CoV-2 infection. The protocol used was as per the manufacturer's instructions. Briefly, the kits are provided with ELISA plates that are coated with the recombinant $\mathrm{S} 1$ domain of the spike protein of SARS-CoV-2 expressed in the human cell line, HEK 293. All the reagents for developing the ELISA are provided within the kit such as: Calibrator (human IgG, IgA, respectively), 
Table I. Demographic characteristics of the enrolled subjects.

\begin{tabular}{lccc}
\hline Demographic & Previously infected subjects, $\mathrm{n}(\%)$ & Non-infected subjects, $\mathrm{n}(\%)$ & Total sample, $\mathrm{n}$ \\
\hline Subjects & $16(23)$ & $53(77)$ & 69 \\
Female & $14(23)$ & $48(77)$ & 62 \\
Male & $2(29)$ & $5(71)$ & 7 \\
Average age of total, years & 37.81 & 41.00 & 40.26 \\
Average age of women, years & 39.14 & 41.48 & 40.95 \\
Average age of men, years & 28.50 & 36.40 & 34.14 \\
\hline
\end{tabular}

Positive control (human $\mathrm{IgG}$, IgA, respectively), negative control (human IgG, IgA respectively), enzyme conjugate peroxidase-labeled anti-human IgG/IgA, sample buffer, wash buffer, chromogen/substrate solution $\mathrm{TMB} / \mathrm{H}_{2} \mathrm{O}_{2}$, stop solution $0.5 \mathrm{M}$ sulphuric acid, quality control certificate.

According to the manufacturer's recommendations, the photometric measurement was performed at $450 \mathrm{~nm}$ with a reference wavelength at 620 and $650 \mathrm{~nm}$, using a multi-reader platform (Varioskan Flash; Thermo Fisher Scientific). Results were calculated as indicated, namely the Ratio between the Extinction of the patient sample and the Extinction of the calibrator. The manufacturer recommends the following cut-off values: ratio $<0.8$; borderline ratio $\geq 0.8$ to $<1.1$; positive ratio $\geq 1.1$. The results are presented as indexes, as recommended by the $\operatorname{IgG}$ and $\operatorname{IgA}$ kit supplier. When appropriate, data are presented as the mean \pm standard deviation (SD) of individual data.

Statistical analysis. We have performed repeated measures ANOVA for all the tested groups. We applied Bonferroni post hoc test to calculate P-values according to Bonferroni-adjusted $\alpha$. GraphPad Prism 8.0 (GraphPad Software, Inc.) was used for data analysis.

\section{Results}

Dynamics of IgG and IgA antibodies prior to vaccination. Between May to September 2020 the study group was followed-up for the serum levels of specific IgG and IgA antibodies. In Fig. 1, we present the registered dynamics for the months May-July, this snapshot example indicates that most of the subjects had negative levels of circulating IgG and that during the registered period, the subjects that were infected exhibited a marked increase in the levels of specific antibodies. The levels in convalescent healthcare workers decreased during this time period.

Serum IgG levels analyzed between the period of May-September revealed the values of infected healthcare workers during this follow-up. The mean value of the IgG index in non-infected and infected subjects was constant during this follow-up period and remained unaltered during these months (Fig. 2).

\section{Vaccination parameters}

Antibodies' levels prior to vaccination. Out of the entire study group, $>23 \%$ of the subjects were previously documented

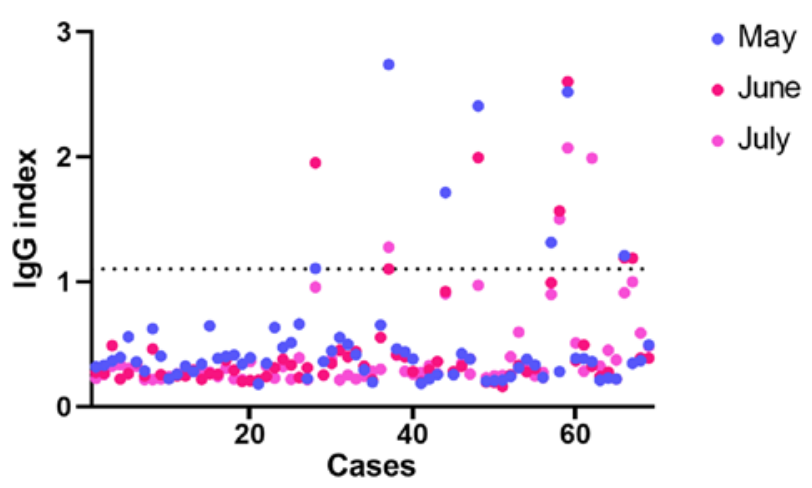

Figure 1. IgG index dynamics between May-July 2020 in the investigated group. Dotted line depicts the positive IgG index.

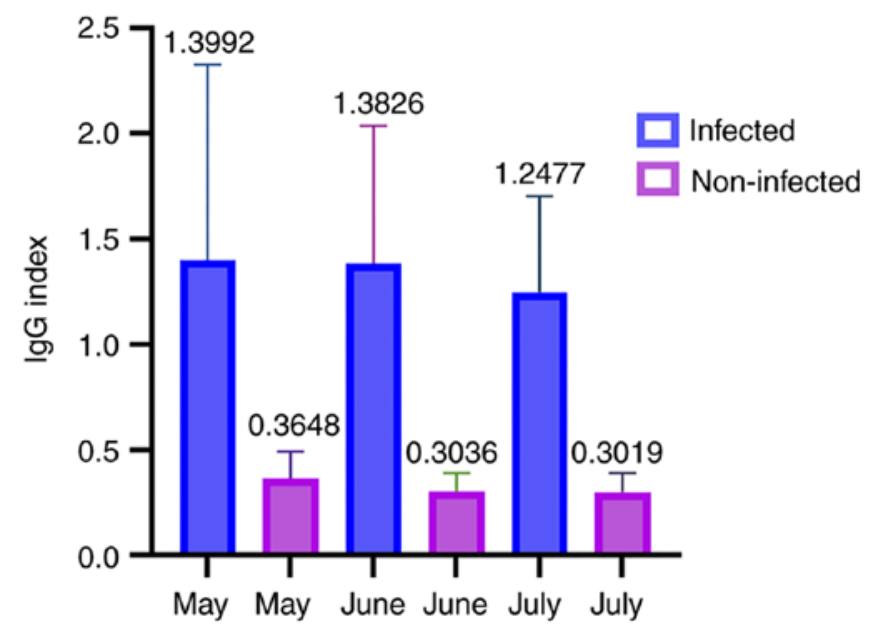

Figure 2. IgG index dynamics between May-July 2020 in the investigated group (mean value and standard deviation).

to have contracted the SARS-CoV-2 infection during this pandemic and prior to the time of vaccination.

The values of both specific $\operatorname{IgG}$ and $\operatorname{Ig}$ A were significantly higher compared with the non-infected subjects prior to vaccination (Table II). In the non-infected subjects, the SD of the mean was low, while it was higher in the infected subjects. The higher SD of value registered for the antibody levels in previously infected subjects prove a higher variability of the antibody's responses to infection due to a specific/individual immune response and correspondingly due to variable time from the disease onset. Owing to these statistically significant 
Table II. IgG and IgA indexes before and after vaccination.

\begin{tabular}{lccc}
\hline Index means & Non-infected subjects, mean & Previously infected subjects, mean & All samples, mean \\
\hline IgG pre-vaccination & 0.42 & 3.02 & 1.02 \\
IgA pre-vaccination & 0.44 & 2.29 & 0.87 \\
IgG after first shot (21 days) & 4.03 & 6.86 & 4.69 \\
IgA after first shot (21 days) & 3.05 & 7.31 & 4.03 \\
IgG after second shot (45 days) & 8.13 & 9.56 & 8.46 \\
IgA after second shot (45 days) & 8.41 & 10.95 & 9.00
\end{tabular}

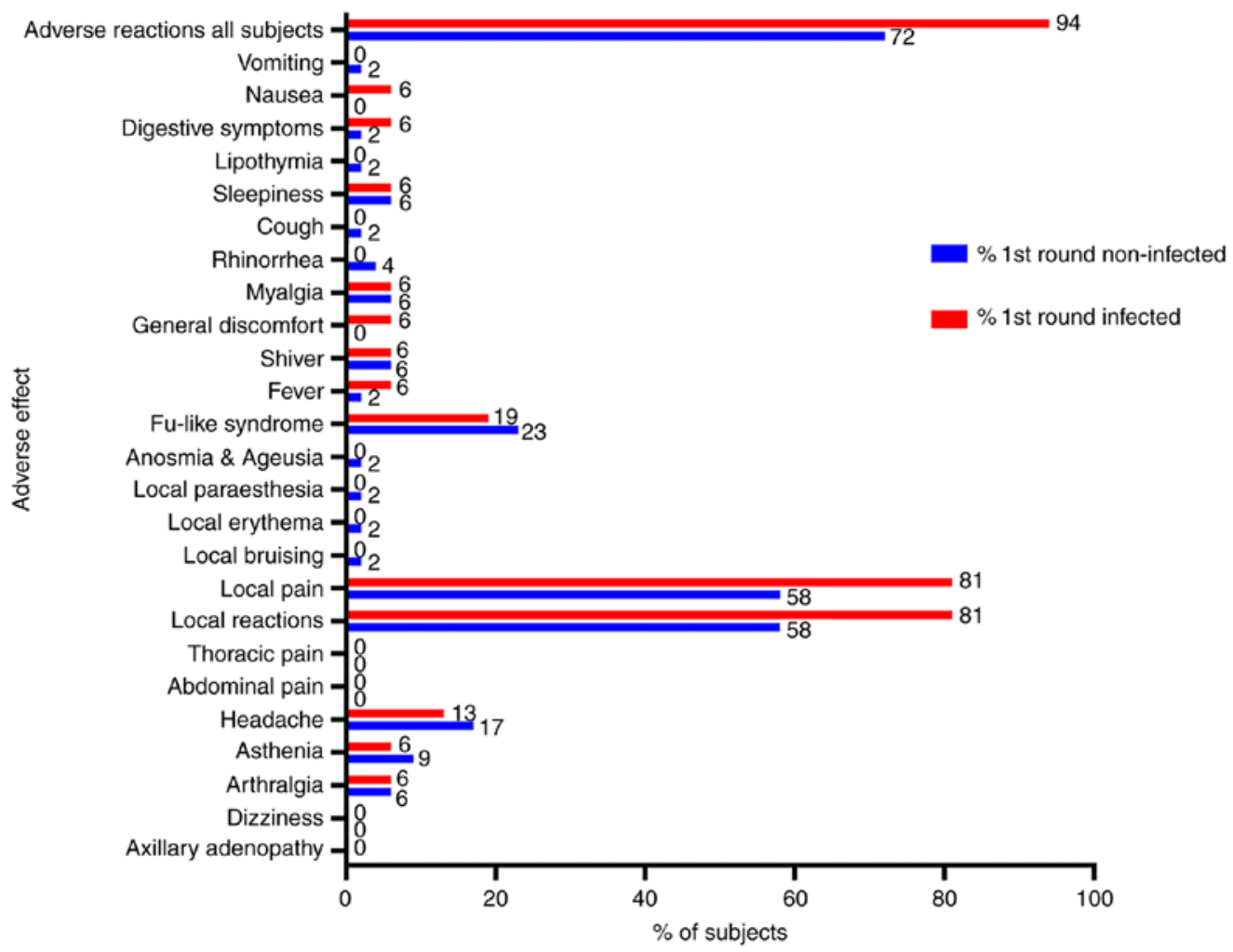

Figure 3. Types of adverse effects noted following first round of vaccination in the investigated group. Numbers in each column represent the percentage of individuals that reported each type of adverse effect.

differences, the post-vaccination dynamics are presented separately for previously infected and non-infected subjects.

Regardless of being in the previously infected or non-infected group, the IgG or IgA levels prior to vaccination were not associated with age or gender. The level of IgG was elevated 7-fold in previously infected compared with non-infected subjects, while the IgA the level was elevated 5 -fold in previously infected compared with non-infected subjects (Table II).

Adverse effects upon vaccination. The presence of any adverse effects was determined upon the first and second round of vaccination for each subject. The adverse effects and the percentage of these recorded adverse effects within both groups is presented in Fig. 3 for the first shot and in Fig. 4 for the second one (see also Table SII). Moreover, no association between the presence of adverse effects with age and gender was observed.
Of all the adverse effects, pain at the inoculation site was present in the majority of patients in the first round $(58.49 \%$ in non-infected subjects, $81.25 \%$ of infected subjects) and in the second round of vaccination (39.62\% in non-infected subjects, $68.75 \%$ of infected subjects). The second most common adverse effects were flu-like symptoms reported in the first ( $22.64 \%$ in non-infected subjects, $18.75 \%$ of infected subjects) and second round of vaccination $(60.38 \%$ in non-infected subjects, $62.50 \%$ of infected subjects). The rarest adverse effects recorded were local bruising, erythema and paresthesia (one case), anosmia and ageusia, lipothymia, cough, nausea, vomiting (one case each after first shot), and axillary adenopathy and local bruising (one case each after second shot). Yet, the vaccination imposed mild adverse effects in the entire study group, with a slight increase in the percentage of adverse effects in previously infected subjects. The assertion was verified in both the first and second round of vaccination. However, the adverse reactions after the first dose of 


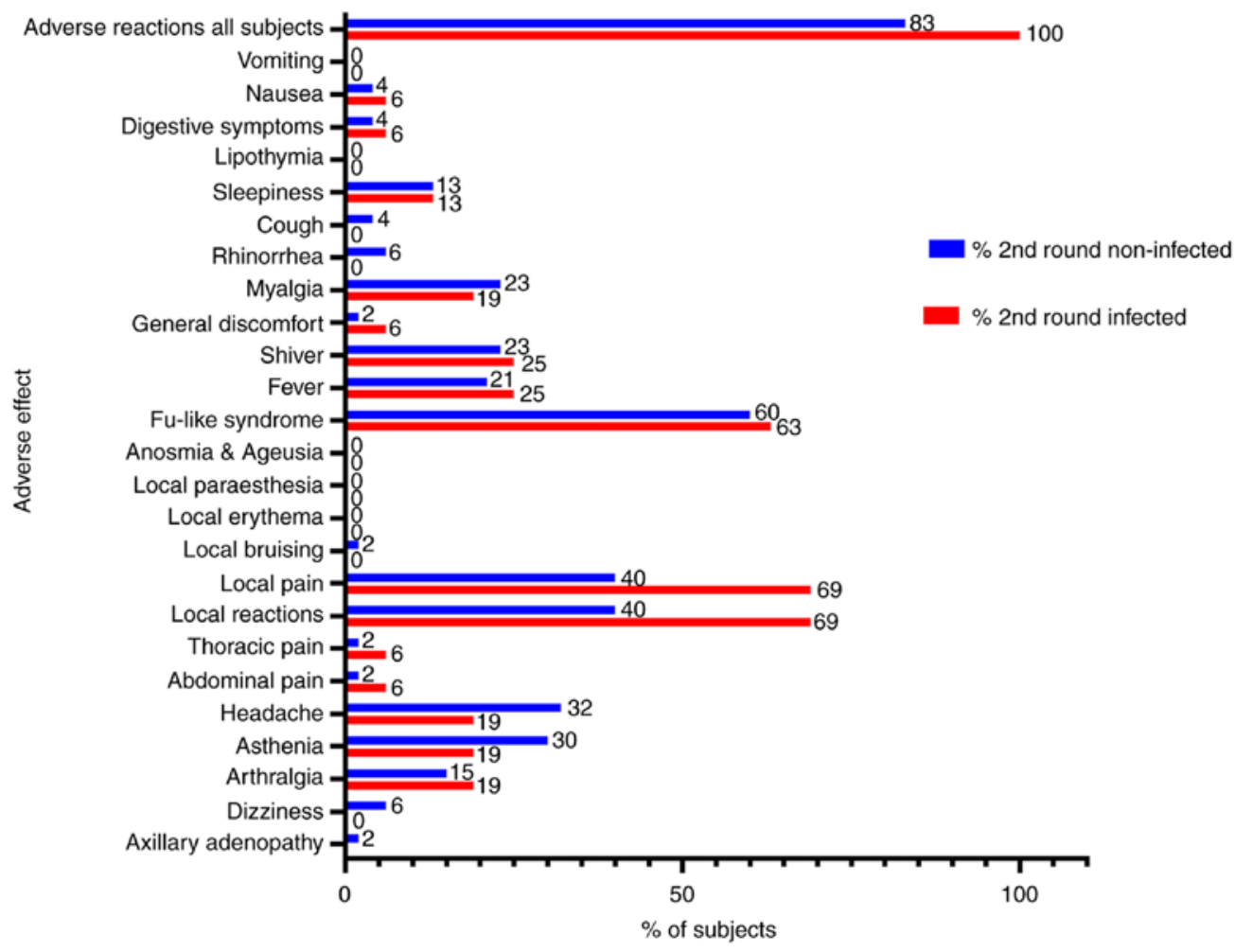

Figure 4. Types of adverse effects noted following second round of vaccination in the investigated group. Numbers in each column represent the percentage of individuals that reported each type of adverse effect.
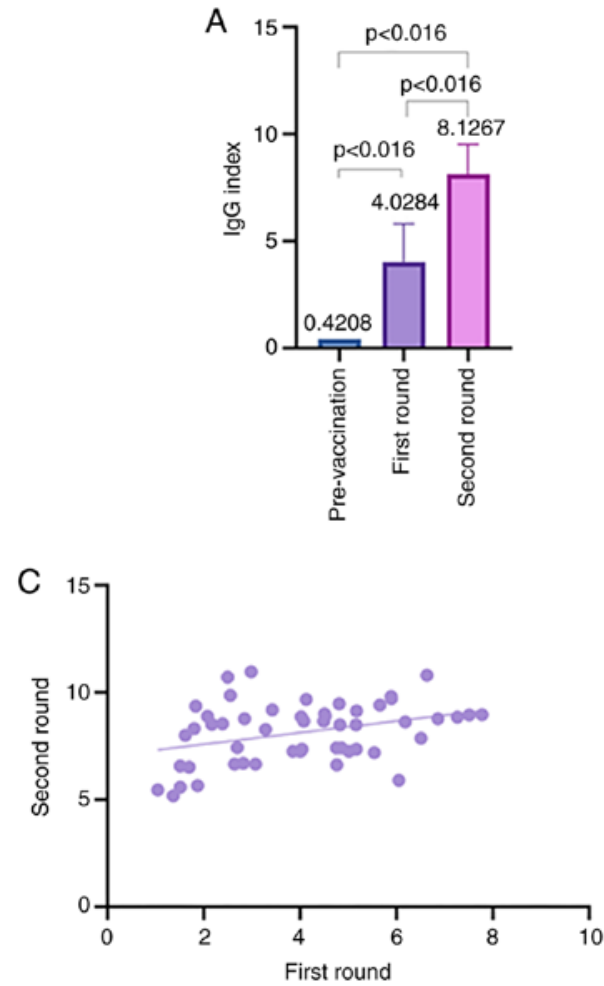
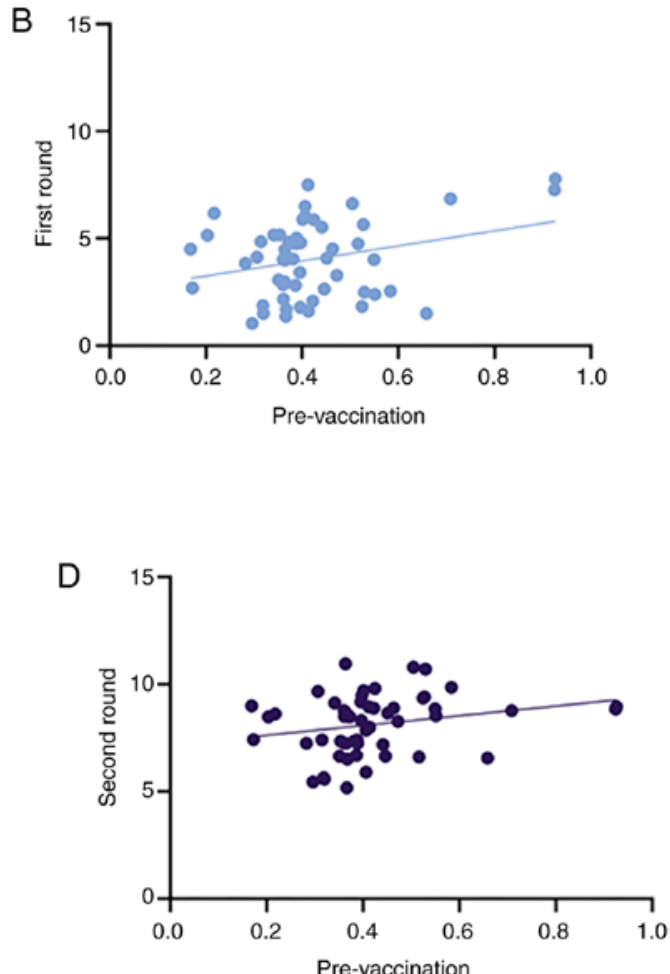

Figure 5. IgG index in non-infected subjects. (A) IgG index in non-infected subjects following the first and second rounds of vaccination. (B) Scatter plot for IgG index in non-infected subjects of pre-vaccination and following the first round of vaccination (21 days). (C) Scatter plot for IgG index in non-infected subjects following the first ( 21 days) and second (45 days) rounds of vaccination. (D) Scatter plot for IgG index in non-infected subjects of pre-vaccination and following the second round of vaccination (45 days).

vaccination in previously infected subjects were not similar in frequency with those noted after the second dose of vacci- nation in non-infected subjects, as one would expect (i.e., the first dose of vaccination in subjects previously infected with 
Table III. Statistical out lines of repeated measures ANOVA.

A, IgG index in the naïve subject group

\begin{tabular}{lrrrrr}
\hline Source of variation & \multicolumn{1}{c}{ SS } & df & MS & F & P-value \\
\hline Rows & 123.111261 & 52 & 2.367524 & 1.714723 & 0.010171 \\
Columns & $1,575.69727$ & 2 & 787.8486 & 570.6139 & $8.57 \mathrm{E}-57$ \\
Error & 143.5931642 & 104 & 1.380704 & & 3.083706 \\
Total & $1,842.401696$ & 158 & & & \\
\hline
\end{tabular}

$\mathrm{B}, \operatorname{IgG}$ index in the previously infected subjects group

\begin{tabular}{lcrrrr}
\hline Source of variation & SS & df & MS & F & P-value \\
\hline Rows & 57.19408843 & 15 & 3.812939 & 1.966985 & 0.100866 \\
Columns & 57.99053419 & 1 & 57.99053 & 29.91563 & $6.46 \mathrm{E}-05$ \\
Error & 29.07703675 & 15 & 1.938469 & & 4.543077 \\
Total & 144.2616594 & 31 & & & \\
\hline
\end{tabular}

$\mathrm{C}, \operatorname{Ig} \mathrm{A}$ index in the naïve subject group

\begin{tabular}{lrrrrr}
\hline Source of variation & SS & df & MS & F & P-value \\
\hline Rows & 448.4025381 & 52 & 8.623126 & 1.702135 & 0.011067 \\
Columns & $1,748.404978$ & 2 & 874.2025 & 172.5605 & $9.18 \mathrm{E}-34$ \\
Error & 526.8706159 & 104 & 5.066064 & & 3.083706 \\
Total & $2,723.678132$ & 158 & & & \\
\hline
\end{tabular}

$\mathrm{D}, \operatorname{Ig} \mathrm{A}$ index in the previously infected subjects group

\begin{tabular}{lcrrrr}
\hline Source of variation & SS & df & MS & F & P-value \\
\hline Rows & 393.3714199 & 15 & 26.22476 & 5.42375 & 0.001118 \\
Columns & 105.9619832 & 1 & 105.962 & 21.91483 & 0.000295 \\
Error & 72.52757384 & 15 & 4.835172 & & 4.543077 \\
Total & 571.860977 & 31 & & & \\
\hline
\end{tabular}

COVID-19 did not act as a 'booster' in SARS-Cov2 naïve subjects considering the occurrence of adverse reactions).

Specific IgG levels upon vaccination. The basal level of IgG was differed significantly between the two analyzed groups (Table II) and the levels were elevated $>7$-fold in previously infected subjects compared with non-infected ones. This clear positive level detected in previously infected subjects (mean index $>3$ ) indicated that upon vaccination, this group developed $\mathrm{IgG}$ antibodies through disease and that vaccination led to increased levels (Fig. 5). After the first vaccination dose, the $\operatorname{IgG}$ levels in non-infected subjects exhibited an increase of almost 12-fold increase in males and almost 11-fold increase in females. After the second round of vaccination, the IgG levels increased 1.33-fold in males and 2.11-fold in females, when compared to the first dose. Although in males it seemed that the $\operatorname{IgG}$ response at 21 days was higher compared with that in females, after the second round of vaccination, the $\operatorname{IgG}$ serum seemed to homogenize in both groups, proving that the generated immune response has a plateau that is reached by all subjects. The increase registered upon vaccination in the $\operatorname{IgG}$ level is statistically different when assessed pre-vaccination versus 21 days and data after 21 days compared to registered levels after 45 days (Tables III and IV). Applying repeated measures ANOVA in the group of naïve subjects has emphasized the results showing that the vaccine led to statistically significant differences in IgG level $[\mathrm{F}(2,104)=570.6139, \mathrm{P}<0.05]$. We applied Bonferroni post hoc test and the results showed that all p-values are less than the Bonferroni-adjusted alpha level (Table IV).

In previously infected subjects subjected to vaccination (Fig. 6) we have registered after the first vaccination dose, an increase of 2.47-fold in males and 2.25-fold in females. After the second dose, an increase of 1.82-fold was observed in males and one of 1.33-fold in females. The overall vaccination procedure seemed to increase the levels of $\mathrm{IgG}$ in both males 
Table IV. Bonferroni post hoc test (Bonferroni corrected) 0.0166667 analysis of the repeated measures ANOVA results.

A, IgG index in the naïve subject group

\begin{tabular}{lcr}
\hline Group & P-value (t-test) & Significant \\
\hline Pre-vaccination vs. After 21 days & $4.11859 \mathrm{E}-27$ & Yes \\
After 21 days vs. After 45 days & $5.80142 \mathrm{E}-24$ & Yes \\
Pre-vaccination vs. After 45 days & $3.97412 \mathrm{E}-65$ & Yes
\end{tabular}

$\mathrm{B}, \mathrm{IgG}$ in the previously infected subjects group

\begin{tabular}{llr}
\hline Group & P-value (t-test) & Significant \\
\hline Pre-vaccination vs. After 21 days & $8.16202 \mathrm{E}-05$ & Yes \\
After 21 days vs. After 45 days & $9.77281 \mathrm{E}-05$ & Yes \\
Pre-vaccination vs. After 45 days & $7.73566 \mathrm{E}-10$ & Yes \\
\hline
\end{tabular}

C, IgA index in the naïve subject group

\begin{tabular}{llc}
\hline Group & P-value (t-test) & Significant \\
\hline Pre-vaccination vs. After 21 days & $4.15878 \mathrm{E}-10$ & Yes \\
After 21 days vs. After 45 days & $1.00589 \mathrm{E}-14$ & Yes \\
Pre-vaccination vs. After 45 days & $2.4916 \mathrm{E}-32$ & Yes \\
\hline
\end{tabular}

$\mathrm{D}, \mathrm{IgA}$ index in the previously infected subjects group

\begin{tabular}{lcc}
\hline Group & P-value (t-test) & Significant \\
\hline Pre-vaccination vs. After 21 days & 0.000151896 & Yes \\
After 21 days vs. After 45 days & 0.013922345 & Yes \\
Pre-vaccination vs. After 45 days & $1.33505 E-07$ & Yes \\
\hline
\end{tabular}
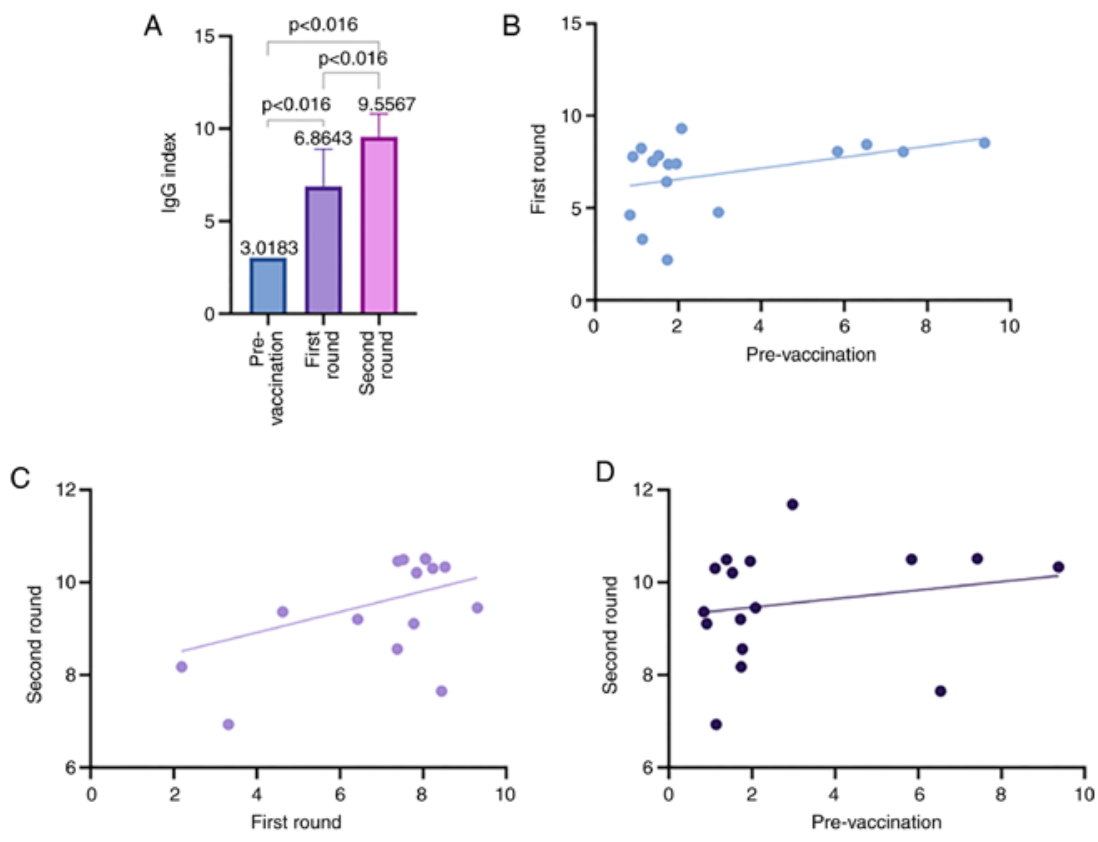

Figure 6. IgG index in the previously infected group. (A) IgG index in previously infected subjects following the first and second rounds of vaccination. (B) Scatter plot for IgG index in previously infected subjects of pre-vaccination and following the first round of vaccination (21 days). (C) Scatter plot for IgG index in previously infected subjects following the first (21 days) and second (45 days) rounds of vaccination. (D) Scatter plot for IgG index in previously infected subjects of pre-vaccination and following the second round of vaccination (45 days). 


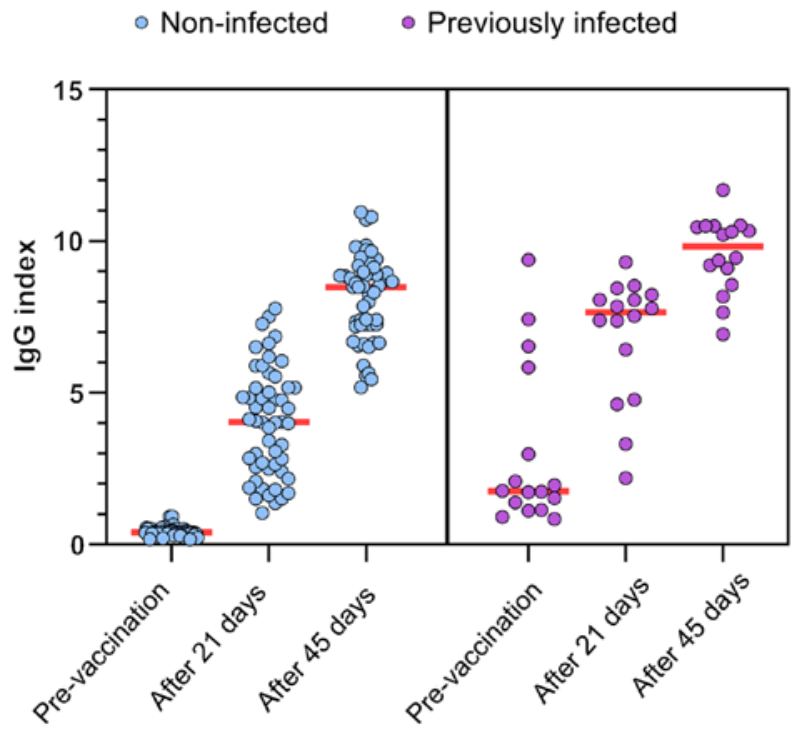

Figure 7. Dispersion of individual IgG indexes at three different periods (pre-vaccination, after 21 days and after 45 days) in naïve and previously infected subjects. Red line depicts the mean value.

and females in previously infected subjects in comparison with uninfected subjects. The increase registered upon vaccination in the prior infected subjects in the IgG level is statistically different when assessed pre-vaccination versus levels after 21 days and $\operatorname{IgG}$ levels after 21 days compared to the 45 days registered levels (Fig. 6). The data of the groups come from the same individuals followed as indicated above and the dispersion of individual $\mathrm{IgG}$ indexes for each subject at moments of pre-vaccination, after 21 days and 45 days is presented in Fig. 7. In infected group, applying repeated measures ANOVA has shown that the vaccine induced statistically significant differences in $\operatorname{IgG}$ level $[\mathrm{F}(1,15)=29.91563, \mathrm{P}<0.05]$ and Bonferroni post hoc test emphasized all p-values as less than the Bonferroni-adjusted alpha level (Table IV).

Specific IgA levels upon vaccination. Similar to the serum levels registered for IgG, the levels registered for IgA differed between the two groups. These levels were elevated $>5$-fold in previously infected subjects compared with naïve ones (Table II). In the non-infected (naïve) subjects, upon the first vaccination dose, the level of IgA (Fig. 8) seemed to be lower compared with the level of IgG in the same subjects. When applying statistics in naïve subjects for IgA levels, similar differences were found in comparison to $\mathrm{IgG}$ levels. Therefore, repeated measures ANOVA has shown that the vaccine induced statistically significant differences in $\operatorname{Ig} \mathrm{A}$ level $[F(2,104)=172.5605, P<0.05]$ and Bonferroni post hoc test emphasized all p-values as less than the Bonferroni-adjusted alpha level (Tables III and IV).

In the previously infected group, the first vaccination dose induced a higher level of IgA compared with the level of IgG in the same subjects. In the non-infected group, after the second vaccination dose, the IgA levels increased compared with the IgG levels.

While in non-infected subjects' females and males seem to have a similar increase of $\operatorname{IgA}$, after the second round of vaccination, the mean value obtained in male subjects is increased compared to females. In the prior infected group, the first dose increases the IgA level similar in females and males
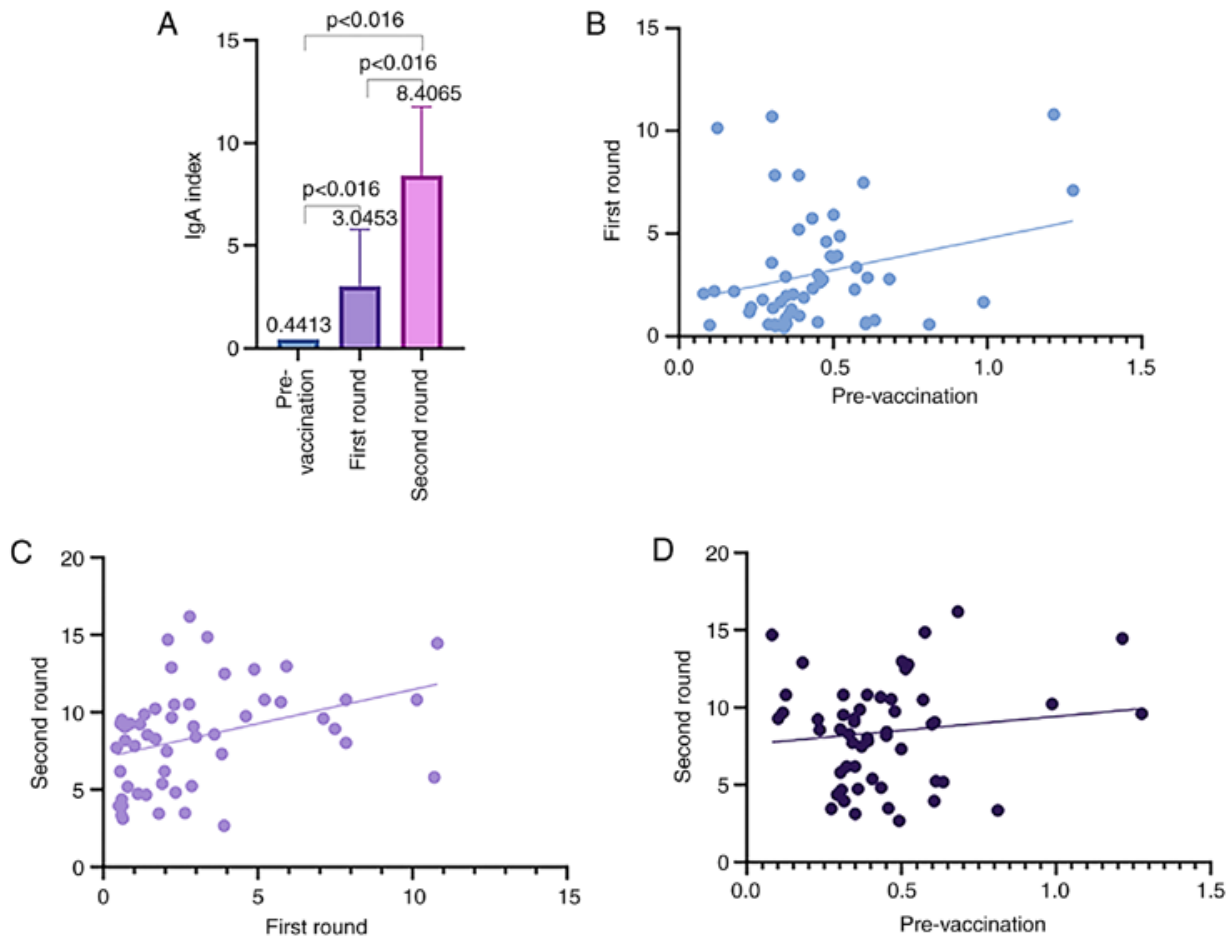

Figure 8. IgA index in non-infected subjects. (A) IgA index in non-infected subjects following the first and second rounds of vaccination. (B) Scatter plot for IgG index in non-infected subjects of pre-vaccination and following the first round of vaccination (21 days). (C) Scatter plot for IgG index in non-infected subjects following the first ( 21 days) and second (45 days) rounds of vaccination. (D) Scatter plot for IgG index in non-infected subjects of pre-vaccination and following the second round of vaccination (45 days). 

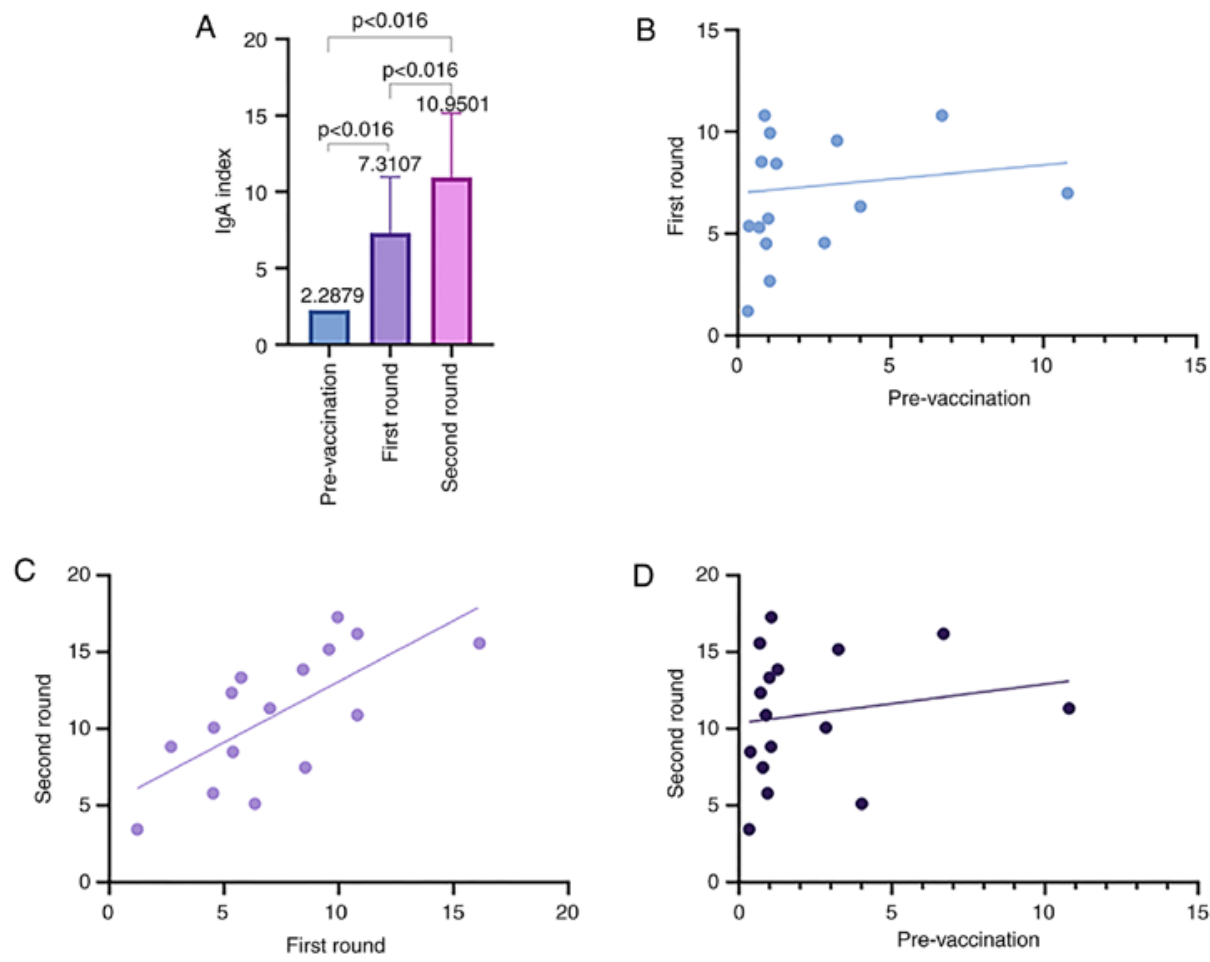

Figure 9. $\operatorname{Ig} \mathrm{A}$ index in the previously infected group. (A) IgA index in previously infected subjects following the first and second rounds of vaccination. (B) Scatter plot for IgA index in previously infected subjects of pre-vaccination and following the first round of vaccination (21 days). (C) Scatter plot for IgA index in previously infected subjects following the first (21 days) and second (45 days) rounds of vaccination. (D) Scatter plot for IgA index in previously infected subjects of pre-vaccination and following the second round of vaccination (45 days).

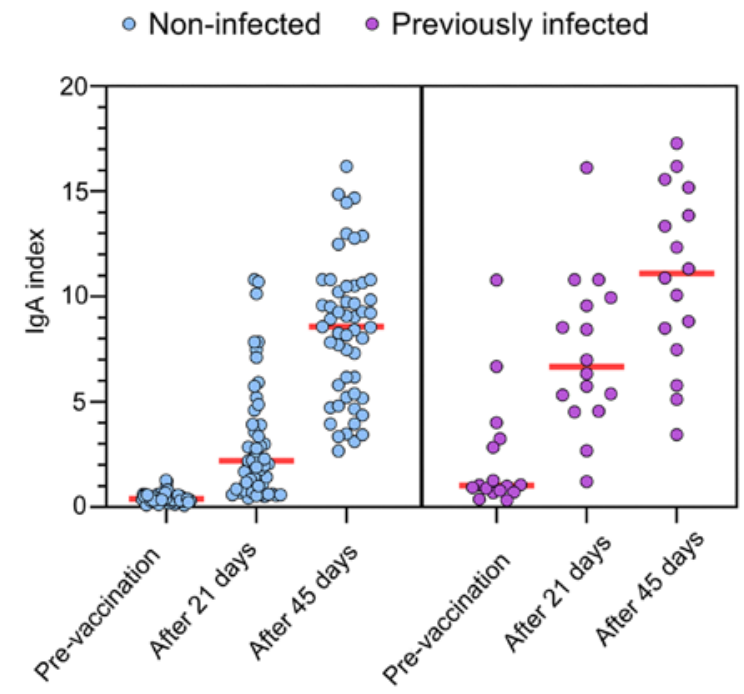

Figure 10. Dispersion of individual IgA indexes at three different periods (pre-vaccination, 21 days and 45 days) in non-infected and previously infected subjects. Red line depicts the mean value.

(3.19 times in females and 3.21 times in males, respectively). The second dose induces the highest registered levels in both males and females at similar levels (Fig. 9). Similar to the $\mathrm{IgG}$ levels, in the $\operatorname{IgA}$ case the dispersion of individual distribution of IgA indexes for each subject at moments of pre-vaccination, after 21 days and 45 days is presented in Fig. 10. In previously infected subjects repeated measures ANOVA has shown that the vaccine induced statistically significant differences in $\operatorname{IgA}$ level $[\mathrm{F}(1,15)=21.91483, \mathrm{P}<0.05]$ and Bonferroni post hoc test emphasized all P-values as less than the Bonferroni-adjusted alpha level (Tables III and IV).

The associations between the IgG and IgA levels upon the first and second dose of vaccination indicated that in the entire vaccination group, regardless of prior exposure to the infectious agent, the increment and levels of $\operatorname{IgG}$ and $\operatorname{IgA}$ were similar (Fig. 11). Therefore, the levels upon vaccination were statistically similar regardless of the starting baseline prior to vaccination (Tables III and IV).

When analyzing all possible associations, the most significant one was the $\operatorname{IgG}$ index after the first dose that induced an antibody response in naïve (non-infected) subjects $<28 \%$ in females compared with males (Fig. 12). A possible explanation for this difference, as previously demonstrated by us (14) and other groups (15), is the hormone-dependent immune response that induces different antibody dynamics. Moreover, even the clinical outcome of COVID-19 was recently reported as correlated with gender (16).

In the present study, seroconversion was achieved in $98.5 \%$ of subjects after the first dose for $\operatorname{IgG}$ and $81 \%$ for $\operatorname{IgA}$, and in $100 \%$ of the entire group after the second dose with highly similar antibody levels.

\section{Discussion}

Up to date there are several approved vaccines that are already applied into the vaccination protocols along with the one that was analyzed herein. Another mRNA-based vaccine developed by Moderna has shown in the NCT04470427 trial tests that is capable to develop specific antibodies $(17,18)$. Another type of vaccine that is as well applied on a large 


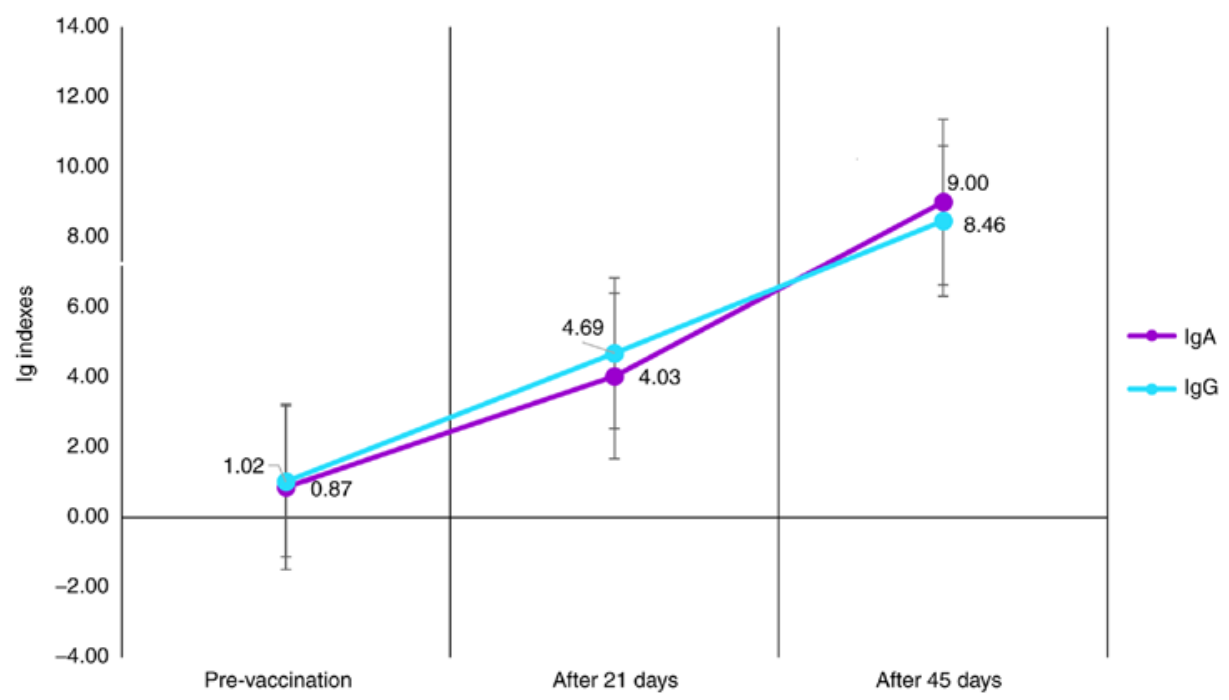

Figure 11. Mean index levels and standard deviation registered for IgG and IgA compared with the entire study group before and after the first round (21 days), and after the second round ( 45 days) of vaccination.

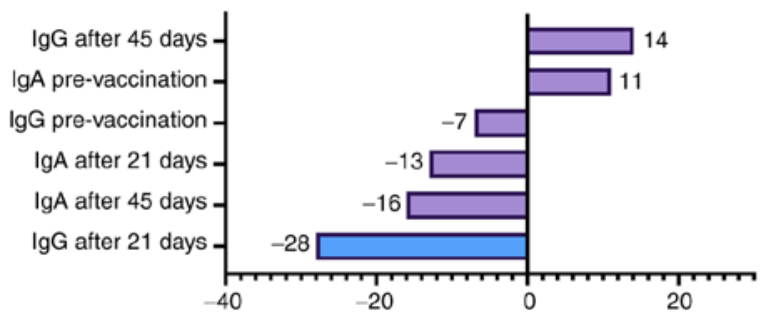

Figure 12. Evolution of antibody levels ( $\operatorname{IgG}$ and $\operatorname{IgA}$ ) induced by the first and second rounds of vaccination in women vs. men. Non-infected women developed an antibody response $<28 \%$ compared with men.

scale (AZD1222) has a different design than the mRNA-based vaccines. AZD1222 is based on the replication-deficient simian adenovirus vector $\mathrm{ChAdOx} 1$, containing the gene of $\mathrm{S}$ glycoprotein. This vaccine was shown to induce antibodies in vaccinated subjects (19). Therefore, the COVID-19 vaccines that are on large scale application around the world seem to induce the intended specific immune response. Questions still remain to be answered regarding how long this immunity will offer protection and if the new variants that are appearing would be neutralized by the antibodies raised to these vaccination platforms. It seems that, at least for the time being, data indicate that these vaccines induce a significant increase in binding antibodies to spike protein of SARS-CoV-1, MERS, and to the four common coronaviruses, currently circulating in the UK. Therefore, there are good news in terms of the specific immune response that can fight also other viral variants and possibly the newly emergent ones (20).

Over the past year, almost 300 studies have become available in the PubMed database focusing on humoral and cellular immunity in COVID-19 patients; however, to the best of our knowledge, there are a handful of reports focusing on the real-case scenario upon vaccination. We have learned some lessons from investigating the immunity of infected patients. Therefore, upon disease high titers of specific IgG levels with serum-neutralizing viral potency in a pseudo-type entry assay were reported (21). Moreover, a strong correlation was found between antibody titers and the percentage of virus-specific $\mathrm{T}$ cells (22). Research on seroprevalence has revealed that seropositive samples were found as early as mid-February, and our results obtained during the summer of 2020 have shown that seroprevalence is stable, suggesting lasting antibody serum levels in subjects as obtained by another group (23). We have chosen ELISA testing because most serological studies embrace the quantitative ELISA platform (24). The ELISA test that we have used (EUROIMMUN Anti-SARS-CoV-2 ELISA Assay) was evaluated, validated and it is comprised in the FDA recommended lists of immunoassays to be used in current pandemia. This type of analysis has proven to have good sensitivity for the detection of $\operatorname{IgA}$ and excellent sensitivity for the detection of $\mathrm{IgG}$, as early as $\geq 4$ days after the diagnosis of COVID-19 by RT-PCR, with no cross-reactivity to common human coronaviruses infection, types NL63 and OC43 (25). In the present study, seroconversion was achieved in $98.5 \%$ of subjects after the first dose for $\operatorname{IgG}$ and $81 \%$ for $\operatorname{IgA}$, and in $100 \%$ of the group after the second dose, with highly similar antibody levels; these results were similar to those of a recent report on a small, vaccinated group of oncological patients (26).

The fact that the specific IgG level followed the level of $\operatorname{IgA}$ is proof that the generated immune response upon vaccination stimulates multiple B lymphocyte clones. Moreover, previously infected subjects exhibited both IgG and IgA levels, detectable even after 8 months post-infection, as we evidenced in the present study group with one case exhibiting positive antibody levels after 8 months. Our results are in accordance with the reported humoral immune response to SARS-CoV-2 infection that shows an early response of $\operatorname{IgA}$, instead of $\operatorname{IgM}(27)$.

Gender association with the post-vaccination level revealed no association, as no associations were observed with the degree of adverse effects and prior encounters with the viral agent. Even though the presence of adverse effects seemed a bit higher in the subjects that experienced the disease in comparison to naïve subjects. We do not rule out that a larger group of subjects would have unveiled statistical differences associated with age and gender. Similar results showed that in a cohort of the same vaccine recipients post-vaccine symptoms 
were more prominent for prior infected subjects after the first dose, but overall symptomology was similar between groups after the second dose (28).

For subjects that still had positive levels of IgG and IgA occurring after infection, the levels at the first dose and second dose were slightly increased compared with the ones registered in uninfected subjects. Results reported in April 2021 have shown that specific IgG antibody levels elicited by a single vaccine dose in prior SARS-CoV-2 infected subjects were similar to those seen after two doses of vaccine in individuals without prior infection (28). In a nested case-control analysis within COVIDsortium (51 participants), a study performed in health-care workers showed that after the first dose of the Pfizer-BioNTech vaccine, the prior infected subjects vaccination increased total antibodies more than 140 -fold in comparison to their pre-vaccine levels (29).

Although the most tested antibodies panel in COVID-19 disease is represented by the IgG and IgM pair, assessing circulating $\operatorname{IgA}$ levels could provide useful insight into the humoral immunity course developed in both patients who were previously infected and those who were vaccinated. $\operatorname{Ig}$ A represents the most abundant antibody class produced in humans, being critical in the first line of antimicrobial defense, by neutralizing pathogens targeting the mucosal boundary (30). IgA comprises different subclasses (IgA1/IgA2) and/or isoforms (monomeric, dimeric/secretory). While the $\operatorname{Ig}$ A circulating form is predominantly monomeric $\operatorname{IgA} 1$ (85\%) and considered as an anti-inflammatory isotype, the dimeric/secretory IgA exhibits both pro- and anti-inflammatory actions (31).

Both circulating and secretory IgA levels present certain distinct features; thus, IgA from serum/plasma originates mainly from bone marrow-derived plasma cells and typically includes the monomeric form, namely IgA1. By contrast, IgA located in mucosa comprises both isoforms, $\operatorname{IgA} 1$ and $\operatorname{IgA} 2$ being produced by plasma cells located in the lamina propria of mucosal surfaces (32).

Even though $\operatorname{Ig}$ A delineates the humoral immunity profile at the mucosal level, it is insufficiently exploited to wholly outline the immune response in the COVID-19 disease context and is almost ignored in post-vaccination studies. Testing serum IgA-specific antibodies in both infected and therefore, in vaccinated subjects is of particular interest since the role and function of $\operatorname{Ig} \mathrm{A}$ in SARS-Cov-2 infection remains uncertain. In addition, both serum and salivary $\operatorname{Ig} \mathrm{A}$ antibody responses have been registered to SARS-CoV-2 spike antigens (33).

The assessment of circulating IgA antibodies in COVID-19 is of equal importance as IgG testing, in order to clarify mostly the asymptomatic and mild cases that typically represent COVID-19 infections (32).

To date, to the best of our knowledge, no data are available regarding IgA circulating levels in vaccinated subjects, and very few in different COVID-19 forms (27). Experience obtained from one year of the COVID-19 pandemic has revealed that SARS-CoV-2-blood $\operatorname{IgA}$ occurrence requires an average seroconversion period of 2-5 days following symptom onset (34), and it is attributed to an early action in SARS-CoV-2 infection, being even more potent than IgG in neutralizing SARS-CoV-2 (35). Regarding the remanence of $\mathrm{IgA}$ in blood, a recent study suggested that the durability of the circulating anti-spike IgA was even up to 8 months following
SARS-CoV-2 infection (36). The authors also observed, in the oldest infected subject, that the levels of IgG and circulatory IgA maintained their positivity.

The potency of serum IgA versus IgG in SARS-Cov-2 infection was recently reported to be associated with the monomeric/dimeric state of IgA. Namely, the serum monomeric $\operatorname{IgA}$ is typically two-fold less effective than IgG, while the dimeric IgA from the mucosal level is significantly more potent than monomer IgA in neutralizing SARS-CoV-2 (37).

When analyzing the data of IgG indexes in subjects with a previous SARS-Cov-2 infection versus subjects without COVID, several hypotheses have emerged. Vaccination induces higher levels of IgG after the first dose of vaccination in not infected subjects (IgG mean index, 4.03) in comparison to the basic levels obtained by subjects through natural immunization (IgG mean index, 3.02). The vaccination of individuals with COVID-19 prior to immunization must be recommended, since the increase in IgG levels is 33\% higher in 'non-COVID' subjects compared to the IgG levels obtained by natural immunization. The vaccination of previously infected subjects with the first dose induces antibody responses slightly lower (IgG mean index, 6.86) than those recorded after the second dose of vaccine in 'non-COVID' subjects (IgG mean index, 8.13). Non-infected subjects have IgG indexes with $21.13 \%$ higher after the second shot compared to previously infected subjects after the first shot. The vaccination of subjects that have experienced the disease with the second dose further increases their IgG levels (IgG mean index, 9.56) by up to $40 \%$ (39.35\% compared with the IgG levels after first dose) and by $17.58 \%$ compared with the IgG levels after the second dose in naïve subjects. Based on this finding, the need for a second shot of the vaccine can be debated in subjects infected with COVID-19 prior to vaccination. The humoral immune response with the capacity to protect against disease obtained after the first vaccination shot in these subjects is excellent, however, a second shot has the capacity to augment it. Perhaps, considering these findings, in the context of the lack of a sufficient vaccine doses worldwide, one might consider an extension of the time period between the first and second dose of the vaccine for subjects with previously SARS-CoV-2 infection.

Similarly, as in the case of the discussions regarding the IgG levels, the findings for the IgA levels can have some original points that should be outlined. Since $\operatorname{IgA}$ is involved mainly in local protection, its levels may be associated with capacity of transmission. Vaccination also induced higher levels of IgA after the first dose in naïve subjects (IgA mean index, 3.05) than basal levels obtained in previously infected subjects (IgA mean index 2.29). To be pointed out that the IgA basal levels of previously infected subjects is high, although, as mentioned, in this sub-group of subjects we have individuals that recovered from the disease even as old as 8 months ago. The increase in the $\operatorname{Ig}$ A levels in non-infected subjects was $33.18 \%$ higher than the levels obtained by natural immunization. Vaccination with the first dose in previously infected subjects induced an IgA response slightly lower (IgA mean index, 7.31) than those recorded after the second dose of vaccination in naïve subjects for $\operatorname{IgG}$ (IgG mean index, 8.41). However, the increase in $\operatorname{Ig} \mathrm{A}$ levels in non-infected subjects after the second shot versus subjects with previous infection after first shot was lower than that of IgG (with 15.04\%). The vaccination of previously 
infected subjects with the second dose markedly increased the IgA levels (IgA mean index, 10.95) by almost half (increase with $49.79 \%$ ) compared with the IgA levels after the first dose and by $30.20 \%$ compared with the IgA levels in naïve subjects after the second dose. Considering the risk of developing COVID-19 after complete vaccination with two shots and implicitly the risk of further dissemination of infection, the second vaccination shot in previously infected subjects induced a potent $\operatorname{IgA}$ response that may provide supplementary protection against transmission.

We are pointing out that serology testing is important prior to vaccination to analyze quickly the humoral immune status of the subject, so that the following vaccination protocol could be adapted. The same conclusion was published in March 2021 by Manisty et al, stating that this testing can induce a prioritization use of the Pfizer booster doses for individuals that did not experience the disease. This approach could accelerate vaccination and, facing new virus variants (UK, South Africa, Brazil), achieving herd immunity quickly, stopping the spreading and hindering new variants emergence (38).

The present study has some limitations regarding the monitored specific response. Although antibody-mediated immunity was followed, the understanding of cellular immunity upon vaccination in this group could have revealed additional aspects. Studies published at the end of 2020 have shown that in the phase I/II trial in healthy adults receiving this type of vaccine after two doses elicited robust $\mathrm{CD}^{+}$and $\mathrm{CD} 8^{+} \mathrm{T}$ cell responses in correlation with strong $\mathrm{IgG}$ responses, levels that were found increased in comparison to individuals post-COVID-19 (39). Thus, in our study, a focus on cellular immunity, namely memory $\mathrm{B}$ and $\mathrm{T}$ cells would have broadened the investigation regarding the vaccination outcome. Another limitation of our study is that direct neutralizing antibodies would have pin-pointed the actual efficacy of vaccination. Of note, during the follow-up period in the present study, immunized subjects did not become re-infected, although in some cases, close un-vaccinated family members developed the infection. In a preliminary study published in March 2021 regarding neutralizing antibodies induced by the same vaccine has shown that neutralizing antibodies concentrations post-vaccination are superior from those observed among COVID-19 human convalescent serum (40). Another limitation of the study is the low number of participants. This limitation is surmounted by the fact that the group is thoroughly investigated and monitored through-out this pandemic regarding co-morbidities, side effects of vaccination and the overall evolution of their health during a possible infection and post-infection. All these clinical data are somewhat difficult to be obtained from large data bases.

The present study aimed to analyze the profiles and dynamics of immunization raised through vaccination between a homogenous group of healthcare workers, and thus to create a clear-cut tool which may be used to assess the intensity and duration of humoral immunity comprising specific antibodies (IgG and $\operatorname{IgA}$ ) to key proteins from SARS-CoV-2 (e.g., Spike protein). The authors aim to perform further studies, analyzing antibody persistence and the presence of memory immune cell populations. Indeed, the whole picture of anti-SARS-Cov-2 immunity, and the post-vaccination status in particular, should encompass both humoral and cellular immunity corroborated parameters. However, the methods through which these humoral immunity figures could be extrapolated to evaluate the infection 'mimicked' by vaccination remain to be determined.

In conclusion, far from being an exhaustive study on vaccination, the present study has evaluated, in a homogenous healthcare workers group, the antibody levels prior and post-vaccination. It was demonstrated that the vaccine induced high levels of specific IgG and $\operatorname{IgA}$ in all the tested subjects. The vaccine induced levels of antibodies that were statistically equivalent regardless of the prior infection. In the present study, seroconversion was achieved in $100 \%$ of the group for both tested antibodies after vaccination protocol completion with highly similar antibody levels.

\section{Acknowledgements}

Not applicable.

\section{Funding}

The present study was supported by the Executive Agency for Higher Education, Research, Development and Innovation (UEFISCDI; grant no. PN-III-P1-1.2-PCCDI-2017-341/2018) and the Core Program, with the support of NASR, project PN no. 19/29.01.01.

\section{Availability of data and materials}

The datasets used and/or analyzed during the current study are available from the corresponding author on reasonable request.

\section{Authors' contributions}

SZ, LN, CM, CC and MN contributed to the study design, data collection, statistical analysis, data interpretation and manuscript preparation. MC and CP contributed to data collection and statistical analysis. AB, BM and CS contributed to data collection, statistical analysis and manuscript preparation. SZ, $\mathrm{LN}, \mathrm{BM}, \mathrm{CS}$ and MN confirmed the authenticity of all the raw data. All authors have read and approved the final manuscript.

\section{Ethics approval and consent to participate}

The present study was approved by the Ethics Committee of Colentina University Hospital (approval no. 25/2017) and performed according to the Declaration of Helsinki. Written informed consent was provided by all patients prior to the study start.

\section{Patient consent for publication}

Not applicable.

\section{Competing interests}

The authors declare that they have no competing interests.

\section{References}

1. Constantin C, Neagu M, Diana Supeanu T, Chiurciu V and A Spandidos D: IgY - turning the page toward passive immunization in COVID-19 infection (Review). Exp Ther Med 20: 151-158, 2020. 
2. Neagu M: The bumpy road to achieve herd immunity in COVID-19. J Immunoassay Immunochem 41: 928-945, 2020

3. World Health Organization (WHO): COVID-19 vaccine tracker and landscape. WHO, Geneva, 2020. https://www. who.int/publications/m/item/draft-landscape-of-covid-19-candidate-vaccines. Accessed June 8, 2021.

4. Kaur SP and Gupta V: COVID-19 vaccine: A comprehensive status report. Virus Res 288: 198114, 2020.

5. Tauzin A, Nayrac M, Benlarbi M, Gong SY, Gasser R, Beaudoin-Bussières $G$, Brassard $N$, Laumaea A, Vézina D, Prévost J, et al: A single BNT162b2 mRNA dose elicits antibodies with Fc-mediated effector functions and boost pre-existing humoral and $\mathrm{T}$ cell responses. bioRxiv: doi: 10.1101/2021.03.18.435972 (Preprint).

6. Oliver SE, Gargano JW, Marin M, Wallace M, Curran KG, Chamberland M, McClung N, Campos-Outcalt D, Morgan RL, Mbaeyi S, et al: The Advisory Committee on Immunization Practices' Interim Recommendation for Use of Pfizer-BioNTech COVID-19 Vaccine - United States, December 2020. MMWR Morb Mortal Wkly Rep 69: 1922-1924, 2020.

7. Deva Priya SA, Kavitha S, Venugopal P, Sriram DK and George M: Can mRNA vaccines turn the tables during the COVID-19 pandemic? Current status and challenges. Clin Drug Investig: Mar 23, 2021 (Epub ahead of print).

8. Meo SA, Bukhari IA, Akram J, Meo AS and Klonoff DC: COVID-19 vaccines: Comparison of biological, pharmacological characteristics and adverse effects of Pfizer/BioNTech and Moderna Vaccines. Eur Rev Med Pharmacol Sci 25: 1663-1669, 2021.

9. Liu X, Wang J, Xu X, Liao G, Chen Y and Hu CH: Patterns of IgG and IgM antibody response in COVID-19 patients. Emerg Microbes Infect 9: 1269-1274, 2020.

10. Long QX, Liu BZ, Deng HJ, Wu GC, Deng K, Chen YK, Liao P, Qiu JF, Lin Y, Cai XF, et al: Antibody responses to SARS-CoV-2 in patients with COVID-19. Nat Med 26: 845-848, 2020.

11. Shen L, Wang C, Zhao J, Tang X, Shen Y, Lu M, Ding Z, Huang C, Zhang J, Li S, et al: Delayed specific IgM antibody responses observed among COVID-19 patients with severe progression. Emerg Microbes Infect 9: 1096-1101, 2020.

12. Long QX, Tang XJ, Shi QL, Li Q, Deng HJ, Yuan J, Hu JL, Xu $\mathrm{W}$, Zhang Y, Lv FJ, et al: Clinical and immunological assessment of asymptomatic SARS-CoV-2 infections. Nat Med 26: 1200-1204, 2020

13. Lou B, Li TD, Zheng SF, Su YY, Li ZY, Liu W, Yu F, Ge SX, Zou QD, Yuan Q, et al: Serology characteristics of SARS-CoV-2 infection after exposure and post-symptom onset. Eur Respir J 56 : 2000763,2020

14. Surcel M, Constantin C, Caruntu C, Zurac S and Neagu M: Inflammatory cytokine pattern is sex-dependent in mouse cutaneous melanoma experimental model. J Immunol Res 2017: 9212134, 2017.

15. Bellenghi M, Puglisi R, Pontecorvi G, De Feo A, Carè A and Mattia G: Sex and gender disparities in melanoma. Cancers (Basel) 12: 1819,2020

16. Gebhard C, Regitz-Zagrosek V, Neuhauser HK, Morgan R and Klein SL: Impact of sex and gender on COVID-19 outcomes in Europe. Biol Sex Differ 11: 29, 2020.

17. Ledford $H$ : Moderna COVID vaccine becomes second to get US authorization. Nature Dec 18, 2020 (Epub ahead of print).

18. Prü $\beta$ BM: Current state of the first COVID-19 vaccines Vaccines (Basel) 9: 30, 2021

19. Khani E, Khiali S and Entezari-Maleki T: Potential COVID-19 therapeutic agents and vaccines: an evidence-based review. J Clin Pharmacol 61: 429-460, 2021.

20. Skelly DT, Harding AC, Gilbert-Jaramillo J, Knight ML, Longet S, Brown A, Adele S, Adland E and Brown H; Medawar Laboratory Team, Tipton T, Stafford L, Johnson SA, Amini A, OPTIC Clinical Group, Tan TK, Schimanski L, Huang KYA, Rijal P, et al: Vaccine-induced immunity provides more robust heterotypic immunity than natural infection to emerging SARS-CoV-2 variants of concern. Research Square: doi: 10.21203/rs.3.rs-226857/v1 (Preprint).

21. Hyseni I, Molesti E, Benincasa L, Piu P, Casa E, Temperton NJ, Manenti A and Montomoli E: Characterisation of SARS-CoV-2 lentiviral pseudotypes and correlation between pseudotype-based neutralisation assays and live virus-based micro neutralisation assays. Viruses 12: 1011, 2020

22. Ni L, Ye F, Cheng M-L, Feng Y, Deng YQ, Zhao H, Wei P, Ge J, Gou M, Li X, et al: Detection of SARS-CoV-2-specific humoral and cellular immunity in COVID-19 convalescent individuals. Immunity 52: 971-977.e3, 2020.
23. Stadlbauer D, Tan J, Jiang K, Hernandez MM, Fabre S, Amanat F, Teo C, Arunkumar GA, McMahon M, Capuano C, et al: Repeated cross-sectional sero-monitoring of SARS-CoV-2 in New York City. Nature 590: 146-150, 2021

24. Neagu M, Calina D, Docea AO, Constantin C, Filippini T, Vinceti M, Drakoulis N, Poulas K, Nikolouzakis TK, Spandidos DA, et al: Back to basics in COVID-19: Antigens and antibodies-Completing the puzzle. J Cell Mol Med 25: 4523-4533, 2021.

25. Beavis KG, Matushek SM, Abeleda APF, Bethel C, Hunt C, Gillen S, Moran A and Tesic V: Evaluation of the EUROIMMUN Anti-SARS-CoV-2 ELISA Assay for detection of IgA and IgG antibodies. J Clin Virol 129: 104468, 2020

26. Thakkar A, Pradhan K, Jindal S, Cui Z, Rockwell B, Shah AP, Packer SR, Sica RA, Sparano JD, Goldstein DY, et al: Patterns of seroconversion for SARS-CoV-2 IgG in patients with malignant disease and association with anticancer therapy. Nat Cancer 2: 392-399, 2021.

27. Yu HQ, Sun BQ, Fang ZF, Zhao JC, Liu XY, Li YM, Sun XZ, Liang HF, Zhong B, Huang ZF et al. Distinct features of SARS-CoV-2-specific IgA response in COVID-19 patients. Eur Respir J 56: 2001526, 2020.

28. Ebinger JE, Fert-Bober J, Printsev I, Wu M, Sun N, Prostko JC, Frias EC, Stewart JL, Van Eyk JE, Braun JG, et al: Antibody responses to the BNT162b2 mRNA vaccine in individuals previously infected with SARS-CoV-2. Nat Med: Apr 1, 2021 (Epub ahead of print).

29. Walsh EE, Frenck RW Jr, Falsey AR, Kitchin N, Absalon J, Gurtman A, Lockhart S, Neuzil K, Mulligan MJ, Bailey R, et al: Safety and immunogenicity of two RNA-based COVID-19 vaccine candidates. N Engl J Med 383: 2439-2450, 2020.

30. Mkaddem SB, Christou I, Rossato E, Berthelot L, Lehuen A and Monteiro RC: $\operatorname{Ig}$ A, $\operatorname{IgA}$ receptors, and their anti-inflammatory properties. Curr Top Microbiol Immunol 382: 221-235, 2014.

31. Gayet R, Michaud E, Nicoli F, Chanut B, Paul M, Rochereau N, Guillon C, He Z, Papagno L, Bioley G, et al: Impact of IgA isoforms on their ability to activate dendritic cells and to prime T cells. Eur J Immunol 50: 1295-1306, 2020.

32. Russell MW, Moldoveanu Z, Ogra PL and Mestecky J: Mucosal immunity in COVID-19: a neglected but critical aspect of SARS-CoV-2 infection. Front Immunol 11: 611337, 2020.

33. Isho B, Abe KT, Zuo M, Jamal AJ, Rathod B, Wang JH, Li Z, Chao G, Rojas OL, Bang YM, et al: Persistence of serum and saliva antibody responses to SARS-CoV-2 spike antigens in COVID-19 patients. Sci Immunol 5: eabe5511, 2020.

34. Lu L, Zhang H, Zhan M, Jiang J, Yin H, Dauphars DJ, Li SY, $\mathrm{Li} \mathrm{Y}$ and He YW: Antibody response and therapy in COVID-19 patients: What can be learned for vaccine development? Sci China Life Sci 63: 1833-1849, 2020.

35. Sterlin D, Mathian A, Miyara M, Mohr A, Anna F, Claër L, Quentric P, Fadlallah J, Devilliers H, Ghillani P, et al: IgA dominates the early neutralizing antibody response to SARS-CoV-2. Sci Transl Med 13: eabd2223, 2021.

36. Dan JM, Mateus J, Kato Y, Hastie KM, Yu ED, Faliti CE, Grifoni A, Ramirez SI, Haupt S, Frazier A, et al: Immunological memory to SARS-CoV-2 assessed for up to 8 months after infection. Science 371: eabf4063, 2021.

37. Wang Z, Lorenzi JCC, Muecksch F, Finkin S, Viant C, Gaebler C, Cipolla M, Hoffmann HH, Oliveira TY, Oren DA, et al: Enhanced SARS-CoV-2 neutralization by dimeric IgA. Sci Transl Med 13: eabf1555, 2021.

38. Manisty C, Otter AD, Treibel TA, McKnight Á, Altmann DM, Brooks T, Noursadeghi M, Boyton RJ, Semper A and Moon JC: Antibody response to first BNT162b2 dose in previously SARS-CoV-2-infected individuals. Lancet 397: 1057-1058, 2021

39. Sahin U, Muik A, Derhovanessian E, Vogler I, Kranz LM, Vormehr M, Baum A, Pascal K, Quandt J, Maurus D, et al: COVID-19 vaccine BNT162b1 elicits human antibody and TH1 T cell responses. Nature 586: 594-599, 2020.

40. Lombardi A, Bozzi G, Ungaro R, Villa S, Castelli V, Mangioni D, Muscatello A, Gori A and Bandera A: Mini review immunological consequences of immunization with COVID-19 mRNA vaccines: preliminary results. Front Immunol 12: 657711, 2021.

This work is licensed under a Creative Commons Attribution-NonCommercial-NoDerivatives 4.0 International (CC BY-NC-ND 4.0) License. 